Çukurova Üniversitesi Mühendislik Mimarlık Fakültesi Dergisi, 32(4), ss. 241-252, Aralık 2017

Çukurova University Journal of the Faculty of Engineering and Architecture, 32(4), pp. 241-252, December 2017

\title{
Sac Metallerin Şekillendirilmesinde Farklı bir Uygulama: Plastik Enjeksiyon Kalıplamada Akışkan Basıncıyla Alüminyum Sacın Şekillendirilmesi
}

\author{
Murat ŞEN ${ }^{I}$, Mihrigül ALTAN ${ }^{* 2}$ \\ ${ }^{I}$ Marmara Üniversitesi, Teknoloji Fakültesi, Makine Mühendisliği Bölümü, İstanbul \\ ${ }^{2} Y$ lldız Teknik Üniversitesi, Makine Mühendisliği Bölümü, İstanbul
}

Öz $\quad$ Geliş tarihi: 08.05.2017 Kabul tarihi: 19.12.2017

Plastik enjeksiyon ile kalıplama yöntemi, plastikler için bir imalatı yöntemi olmasına rağmen, sıvı basıncı ile şekillendirme esas alınarak sac metallerin şekillendirilmesi için kullanılabilmektedir. $\mathrm{Bu}$ çalışmada, plastik enjeksiyon makinasında, $1,5 \mathrm{~mm}$ kalınlığındaki alüminyum saclar, polistirenin farklı enjeksiyon basıncı, ergiyik sıcaklığı ve enjeksiyon hızı değerlerinde şekillendirilmiştir Bu parametrelerin sac metalin şekillendirilmesi üzerine etkileri, deneysel ölçüm metotların yanı sıra Taguchi, ANOVA, cevap yüzey metodu ve regresyon analizi teknikleri ile de incelenmiştir. Metalin şekillendirilebilirliği incelenirken, sac metalin şekillendirme sonrası incelme oranı, flanş bölgesindeki yarıçap değeri ve sertlik değerleri dikkate alınmıştır. Yapılan deneysel çalışmanın sonucunda, enjeksiyon basıncının şekillendirme üzerindeki en etkili parametre olduğu ve ikinci dereceden en etkili parametrenin ise ergiyik sıcaklığı olduğu görülmüştür. Şekillendirilen parçanın, merkezinden flanş bölgelerine doğru artan sertlik değeri sonuçları, sac metalin bu bölgelerde yüksek oranda şekillendirilebildiğini doğrulamıştır.

Anahtar Kelimeler: Aluminyum, Hidroforming, İncelme oranı, Plastik enjeksiyon kalıplama, Taguchi

\section{A Novel Application in Sheet Metal Forming: Shaping Metals by Plastic Injection Molding based on Fluid Pressure Forming}

\begin{abstract}
Plastic injection molding, even though it is a manufacturing method for plastics, can be used for forming sheet metals based on fluid pressure forming. In this study, aluminum sheets with $1.5 \mathrm{~mm}$ thikcness were deformed under different injection pressure, melt temperature and injection rate on a plastic injection molding machine. The effects of these parameters on deformability of the sheet metal were investigated by experimental measurement techniques and Taguchi, ANOVA, regression, surface response methods. The thinning rate, radius along the flange and the hardness values were considered. As a result of the experimental study, it has been seen that injection pressure was the first degree effective parameter and melt temperature was the second degree effective parameter on thinning rate. The increment of hardness of the deformed part from center to the flange, verified the high deformability of the sheet metal in these regions.
\end{abstract}

Keywords: Aluminium, Hydroforming, Thinning rate, Plastic injection molding, Taguchi

*Sorumlu yazar (Corresponding author): Mihrigül ALTAN, meksi@yildiz.edu.tr 


\section{GíRiș}

Sac metal malzemelerin şekillendirilmesinde çok sayıda yöntem geliştirilmiş ve kullanılmaktadır. Özellikle derin çekme yöntemi esasına dayanan, sac şekillendirme yönteminde, kusursuz parça imalatı için, doğru kalıp geometrisi, pot çemberi etkisi ve uygun kuvvet değerlerinin belirlenmesi önem arz etmektedir. Derin çekme ile şekillendirilmiş parçalarda aşırı incelme, yırtılma veya flanş bölgesinde yüksek oranda kırışma görülebilmektedir. Bunların giderilmesi için kalıp geometrisi, uygun malzeme seçimi, uygun kalınlıkta sac seçilmesi ve diğer parametrik seçimlere dikkat edilmesi gerekmektedir. Literatürde, derin çekme yöntemi esas alınarak gerçekleştirilmiş, yöntem parametrelerinin şekillendirme üzerine etkilerini görebilmek amacıyla yapılan birçok çalışma mevcuttur [1-5].

Sac metal şekillendirme alanında derin çekme yöntemine alternatif olarak gelişen bir yöntem olan sıvı basıncıyla şekillendirme (hidroforming) işlemi hakkında literatürde çok sayıda çalışma yer almaktadır. $\mathrm{Bu}$ çalışmaların büyük bölümünü farklı proses parametrelerinin şekillendirilebilirlik üzerine etkilerinin incelenmesi oluşturmaktadır. Buna yönelik olarak, Koç ve arkadaşları [6], sıcak hidroforming prosesi ile sac malzemelerin şekillendirilebilirliğini farklı proses parametreleri kullanarak incelemişlerdir. Çalışmalarında 1,0 mm kalınlığında 5000 serisi alüminyum (AA5754-0) malzemesini kullanmışlardır. Sıcaklık, basınç ve pot kuvvetini dikkate alarak, bu parametrelerin proses sonu parça formuna, incelmesine ve boşluk doldurma oranına etkilerini cevap yüzey metodunu kullanarak değerlendirmişlerdir. Çalışma neticesinde şekillendirilebilirlik üzerinde en etkili proses parametresinin sicaklık olduğu sonucuna ulaşmışlardır. Yaşar ve arkadaşları [7], AA 5754 sacın hidroform yöntemi ile şekillendirilebilirliğini incelemiştir. Çalışmalarını, hem oda sıcaklığında, hem de $150{ }^{\circ} \mathrm{C}$ ve $205{ }^{\circ} \mathrm{C}$ gibi iki farklı kalıp sıcaklığında gerçekleştirip, elde ettikleri sonuçları sonlu elemanlar metodu ile karşılaştırmışlardır. Çalışmaların sonucunda, AA 5754 malzemesinin oda sıcaklığında şekillendirilebilirliğinin sınırlı olduğunu, kalıp sıcaklığının etkisi ile malzemenin şekillendirilme kabiliyetinin arttığını görmüşlerdir. Li ve arkadaşları [8], tüp hidroforming yöntemiyle şekillendirilmiş parçalarda maksimum ve homojen bir şekillendirilebilirliği elde edebilmek amacıyla farklı proses parametrelerini kullanarak sonlu elemanlar metoduna dayalı bir çalışma gerçekleştirmişlerdir. Proses sonu en uygun incelme oranına ulaşabilmek için Taguchi deneysel tasarım metodundan faydalanmışlardır. Şekillendirilebilirlik üzerinde en etkili proses parametrelerini sırasıyla sıvı basıncı ve sürtünme katsayısı olarak bulmuşlardır. Parçalarda meydana gelen incelme oranı değerlerinin tahmini için regresyon analizini kullanılarak birinci dereceden tahminsel denklemler geliştirilmişlerdir.

Derin çekme ve sıvı basıncıyla sac metal şekillendirme yöntemlerine alternatif bir yöntem olarak plastik enjeksiyon yönteminin kullanılması ile ilgili bazı çalışmalara rastlanmıştır [9-15]. Plastik enjeksiyon kalıplama yönteminin alışılagelmiş uygulama alanı, plastiklerin imalatı içindir. Ancak sac metallerin şekillendirilmesi için de kullanılabileceği görülmüştür. Literatürde plastik enjeksiyonun metal şekillendirilme için kullanılmasında karşılaşılan uygulamalar, sac metal şekillendirmenin yanı sıra, plastik-metal makro kompozit imalatı da olabilmektedir. Ancak genel prensip itibarıyla çalışmaların özünü, sac metal parçaların istenilen tolerans aralığında, homojen ve maksimum şekillendirilebilmeleri oluşturmaktadır.

Bu konuda, Michaeli ve Measing [9], alüminyum ve paslanmaz çelik malzemelerinin plastik enjeksiyon kalıplama yöntemini kullanarak farklı proses parametrelerinin şekillendirmeye olan etkisini incelemişlerdir. Lucchetta ve Baesso [10], metal ve polimerden oluşan makro-kompozit parçaların imalatını tek operasyonla plastik enjeksiyon kalıplama işlemini kullanarak gerçekleştirmişlerdir. Çalışmalarında farklı enjeksiyon parametrelerinin şekillendirilebilirlik üzerine etkilerini deneysel olarak incelemişlerdir. Enjeksiyon parametreleri olarak enjeksiyon hızını, ergimiş polimer sıcaklığını ve kapama kuvvetini esas almışlardır. Ayrıca polimere ait viskozite ve kalıp sıcaklığı da değerlendirilmeye alınmıştır. Chen ve arkadaşları [11], yeni bir yaklaşım olan 
metal-polimer makro-kompozit parçaların plastik enjeksiyon kalıplama yöntemiyle imalatında, farklı enjeksiyon basınçları altındaki (0-30 $\mathrm{MPa})$ şekillendirilebilirliklerini incelemişlerdir. Çalışmalarında $1,0 \mathrm{~mm}$ kalınlığında, $50 \mathrm{~mm}$ çapında saf alüminyum dairesel plakalar kullanmışlardır. Şekillendirilen parçaların farklı bölgelerindeki gerinim ve kalınlık dağılımlarını sonlu elemanlar yöntemiyle ve deneysel çalışmalarla değerlendirmişlerdir. Altan ve arkadaşları [12], plastik enjeksiyon yöntemini kullanarak hem metali şekillendirmişler hem de şekillendirilmiş sac ve plastik ikilisi ile titreşim sönümleyici metal-polimer makro kompozit yapıların imalatını gerçekleştirmişlerdir. Plastik enjeksiyon kalıplama yöntemi ile farklı enjeksiyon parametrelerini dikkate alarak makro kompozit bir yapı imal etmişlerdir. Tekkaya ve arkadaşları [13], plastik enjeksiyon yöntemi ile sac metallerin şekillendirilmesi üzerine gerçekleştirdikleri çalışmada, sac metal olarak AA-5754 ve polimer malzeme olarak PPH-3060 ile PPH-11012 malzemelerini kullanmışlardır. Çalışmalarında, sac metalin şekillendirilmesinde farklı polimerlerin kullanılmasının etkisini incelemişlerdir. Bariani ve arkadaşları [14], plastik enjeksiyon yöntemi ile şekillendirdikleri metal plakalar ile plastik malzemeden oluşan makro kompozit bir yapı elde etmişler ve bu yapının oluşum sürecini ANSYS mekanik ve ANSYS CFX sonlu elemanlar yazılımlarını kullanarak modellemişlerdir. Çalışmalarını sonlu elemanlar analizlerine ek olarak farklı proses parametrelerinin şekillendirilebilirliğe etkisini deneysel olarak inceleyerek optimum modele ulaşmayı amaçlamışlardır. Behrens ve arkadaşları [15], benzer olarak plastik enjeksiyonla şekillendirme yöntemine dayalı bir çalışma yapmıştır. $\mathrm{Bu}$ çalışmada sac metal parçanın malzeme davranışı, sıcaklığa bağlı elasto-plastik malzeme modeli kullanılarak sonlu elemanlar metoduyla oluşturulmuştur.

Yapılan literatür incelemesinde, derin çekme ve hidroforming yöntemi ile sac şekillendirme üzerine çalışmaların oldukça fazla olduğu ancak plastik enjeksiyon yönteminin, bir sac şekillendirme yöntemi gibi uygulanmasına yönelik çalışmaların kısıtlı sayıda olduğu görülmüştür. Sıvı basıncı ile şekillendirmenin karmaşık şekilli parçaların imalatında oldukça etkili olduğu bilinmektedir. Dolayısıyla, uygulaması oldukça pratik olan plastik enjeksiyon yönteminin, sıvı basıncıyla şekillendirme prensibini esas olarak sac metallerin şekillendirmesi için kullanılmasının hem literatürdeki hem de sanayideki uygulama eksikliğini gidermek adına faydalı olacağı düşünülmüştür. Yapılan çalışmada, plastik enjeksiyon kalıplamadaki proses şartlarından enjeksiyon basınc1, enjeksiyon hızı ve ergiyik sıcaklığı gibi parametreler, farklı seviyelerde göz önüne alınarak bu parametrelerin sac metalin şekillendirilebilirliği üzerine etkileri incelenmiştir.

\section{MATERYAL VE METOT}

\subsection{Malzeme}

Deneysel çalışmada, alüminyum (Al-1050.O) sac metal kullanılmış olup, malzemenin maksimum akma mukavemeti $30 \mathrm{MPa}$ olup, maksimum çekme mukavemeti ise $80 \mathrm{MPa}$ 'dır. Malzemeye ait kimyasal analiz sonuçları Çizelge 1 'de verilmiştir. Kullanılan alüminyum sacın boyutları $76 \mathrm{~mm} \mathrm{x}$ $116 \mathrm{mmx}$ 1,5 mm'dir. Metalin kalıp içinde şekillendirmesi için polistren (LGP Polymers) tercih edilmiştir. Amorf bir yapıya sahip olan polistrenin kendini çekmesinin, kısmi kristalin polimerlere göre çok daha az olması, metalin şekillendirilme süreci için önem arz etmektedir.

Çizelge 1. Al-1050,O kimyasal analiz sonuçları (\%Hacim)

\begin{tabular}{|c|c|c|c|c|c|c|c|}
\hline $\mathrm{Al}$ & $\mathrm{Cu}$ & $\mathrm{Fe}$ & $\mathrm{Mg}$ & $\mathrm{Mn}$ & $\mathrm{Si}$ & $\mathrm{Ti}$ & $\mathrm{Zn}$ \\
\hline 99,5 & 0,05 & 0,4 & 0,05 & 0,05 & 0,25 & 0,03 & 0,07 \\
\hline
\end{tabular}

\subsection{Plastik Enjeksiyonla Sac Metalin Şekillendirilmesi}

Plastik enjeksiyonla sac metal şekillendirme işleminde tek taraflı kalıp kullanılması, kalıp maliyeti, işçiliği ve bakımı açısından üreticiye avantaj sunmaktadır. Geleneksel derin çekme yönteminde alt ve üst kalıp gereksiniminin olması tercihi plastik enjeksiyonla şekillendirme yöntemine kaydırmaktadır. Deneysel çalışmalarda kullanılan kalıp ve boyutları Şekil 1 ve Şekil 2'de 
Sac Metallerin Şekillendirilmesinde Yeni bir Uygulama: Plastik Enjeksiyon Kalıplamada Sivı Basincıyla Metallerin Şekillendirilmesi

verilmiştir. Şekillendirmede, 40 ton'luk plastik enjeksiyon makinesi kullanılmıştır. Yatay pozisyonda çalışan plastik enjeksiyon makinasında, şekillendirme öncesi sac metalin, kalıp üzerinde düşmeden, stabil bir şekilde durabilmesi için kalıba vakum kanalları açılmıştır (Şekil 1).
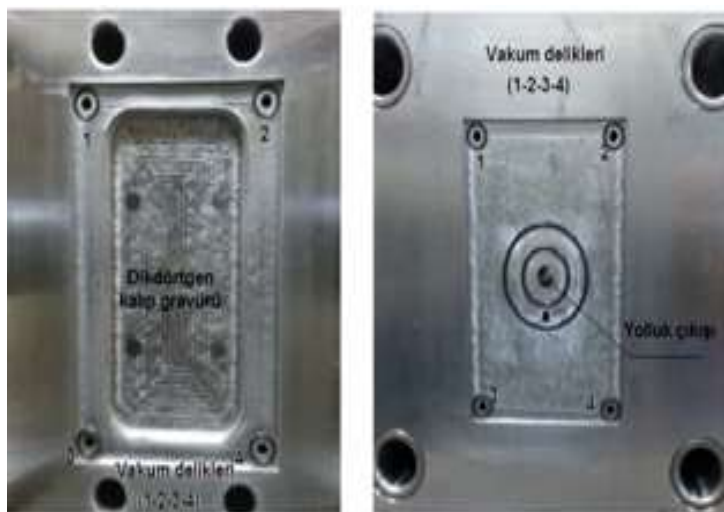

Şekil 1. Deneysel çalışmada kullanılan kalıbın fotoğrafı
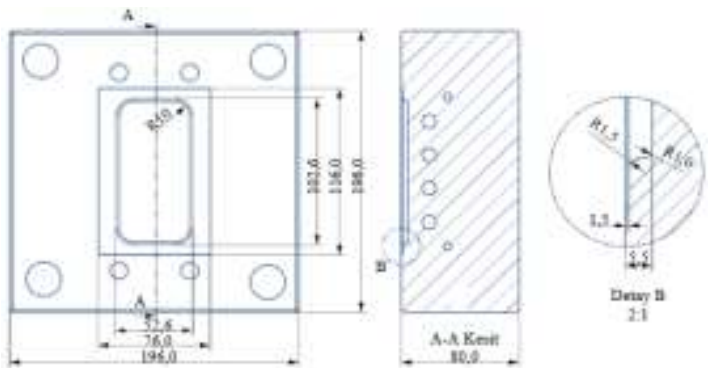

Şekil 2. Kalıbın boyutları (mm)

Deneysel çalışmada, plastik enjeksiyon yönteminde sac metalin şekillendirilebilirliğin incelemek amaciyla kontrol faktörleri olarak; enjeksiyon basıncı, ergiyik polimer sıcaklığı ve enjeksiyon hızı tercih edilmiştir. Bu faktörlere ait seviyeler Çizelge 2'de gösterilmiştir. Deneysel tasarım olarak Taguchi'nin L9 ortogonal matrisi kullanılmıştır (Çizelge 3).

Çizelge 2'de görüldüğü gibi her kontrol faktörüne ait üçer seviye bulunmaktadır. Enjeksiyon basıncı olarak 40, 60 ve $80 \mathrm{MPa}$, ergiyik sicaklığ 1 olarak 200,220 ve $240{ }^{\circ} \mathrm{C}$ ve akıtma hizı olarak 30,32 ve $34(\%)$ değerleri seçilmiştir.
Çizelge 2. Kontrol faktörleri ve seviyeleri

\begin{tabular}{|c|c|c|c|c|c|}
\hline \multirow[b]{2}{*}{$\begin{array}{l}\text { Kontrol } \\
\text { Faktörleri }\end{array}$} & \multirow[b]{2}{*}{ Sembol } & \multicolumn{3}{|c|}{ Seviyeler } & \multirow[b]{2}{*}{ Birim } \\
\hline & & $\sum_{\infty}^{\infty}-$ & $\sum_{\sum_{n}^{\circ}} N$ & $\sum_{\infty}^{\infty} m$ & \\
\hline $\begin{array}{c}\text { Enjeksiyon } \\
\text { Basincı }\end{array}$ & A & 40 & 60 & 80 & Mpa \\
\hline $\begin{array}{c}\text { Ergiyik } \\
\text { Sicaklığı }\end{array}$ & B & 200 & 220 & 240 & ${ }^{\circ} \mathrm{C}$ \\
\hline $\begin{array}{c}\text { Enjeksiyon } \\
\text { Hizı }\end{array}$ & $\mathrm{C}$ & 30 & 32 & 34 & $(\%)$ \\
\hline
\end{tabular}

Çizelge 3. L9 ortogonal matrisi

\begin{tabular}{|c|c|c|c|}
\hline \multirow{2}{*}{ Deney No } & \multicolumn{3}{|c|}{ Semboller } \\
\cline { 2 - 4 } & $\mathrm{A}$ & $\mathrm{B}$ & $\mathrm{C}$ \\
\hline 1 & 1 & 1 & 1 \\
\hline 2 & 1 & 2 & 2 \\
\hline 3 & 1 & 3 & 3 \\
\hline 4 & 2 & 1 & 2 \\
\hline 5 & 2 & 2 & 3 \\
\hline 6 & 2 & 3 & 1 \\
\hline 7 & 3 & 1 & 3 \\
\hline 8 & 3 & 2 & 1 \\
\hline 9 & 3 & 3 & 2 \\
\hline
\end{tabular}

\section{3. İncelme Oranlarının Belirlenmesi}

Şekillendirme sonrası elde edilen parçaların kalınlık değerleri, şekillendirilen parçanın dört eşit parçaya bölünerek parçanın A-A kesiti boyunca ölçülmüştür: (Şekil 3). Ölçme işlemleri optik ölçme yöntemi ile kullanılarak \%0,01 hassasiyetinde gerçekleştirilmiştir.
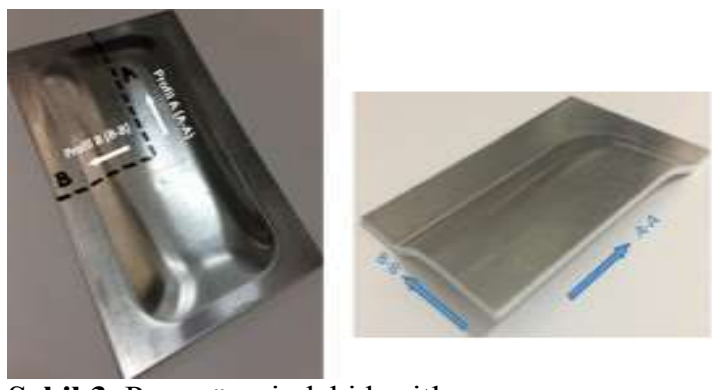

Şekil 3. Parça üzerindeki kesitler

Alüminyum sac metal malzemesinin şekillendirilmesi sonucunda parçanın formunda yırtılma veya tolerans sınırları içerisinde aşırı 
incelme olmaması kaydıyla sac kalınlığına bağlı olarak maksimum şekillendirmeyi elde etmek amaciyla proses sonu meydana gelen incelme miktarının en fazla olması istenmektedir. 1,5 mm sac kalınlığındaki plakalar ile gerçekleştirilen deneyler ve ölçümler neticesinde parça formunda herhangi bir yırtılma ya da aşırı incelme durumuyla karşılaşılmamasından dolayı deneysel tasarımda yer alan sinyal/gürültü $(\mathrm{S} / \mathrm{N})$ oranının hesaplanmasında "Daha büyük daha iyi" ifadesini temsil eden 1 nolu eşitlik esas alınmıştır. $\mathrm{Bu}$ Eşitlikte $n$ deney sayısını, $y_{i}{ }^{\prime}$ de elde edilen $i$. veriyi ifade etmektedir [19].

$$
\mathrm{S} / \mathrm{N}=-10 \cdot \log \left(\frac{1}{\mathrm{n}} \sum_{\mathrm{i}=1}^{\mathrm{n}} 1 / \mathrm{y}_{\mathrm{i}}^{2}\right)
$$

\section{4. Şekillendirme Sonrası Sertlik Ölçümü}

Farklı proses parametrelerinin şekillendirilmiş parçaların sertlikleri üzerine etkilerini görebilmek amacıyla sertlik ölçme işlemleri gerçekleştirilmiştir. $10 \mathrm{~kg}$ ön yükleme ve $100 \mathrm{~kg}$ toplam yük altında, 1/16 bilya ile yapılan ölçüm ile şekillendirilmiş alüminyum parçaların sertlik değerleri ölçülmüştür. Ölçüm öncesi yüzeyler sülfirik asit ve nitrik asit ile temizlenmiştir. Ölçüm sonucunun güvenilir ve doğru olması amacıyla numunelerin enine ve boyuna olmak üzere çok sayıda noktasından sertlik ölçme işlemi tekrar edilmiştir.

\section{BULGULAR VE TARTIŞMA}

\subsection{Plastik Enjeksiyonda Sac Metalin Şekillendirilebilirliği}

Alüminyumun plastik enjeksiyon yöntemi ile şekillendirilebilirliğinin incelenmesinde, incelme oranı, parçanın köşe yarıçapı değerleri ve sertlik değerleri dikkate alınmıştır.

Farklı proses parametreleri kullanılarak gerçekleştirilen deneysel çalışmalar neticesinde dengeli basınç dağılımı ve şekillendirilebilirliğin elde edilebilmesi için yüksek basınç, sıcaklık ve enjeksiyon hızına ihtiyaç duyulmaktadır. L9 ortogonal matrisi esas alınarak gerçekleştirilen deneysel çalışmalarda proses parametrelerinin şekillendirme üzerine etkilerini görebilmek amacıyla şekillendirilmiş parçaların incelme oranları ve "En büyük en iyidir" yaklaşımına göre hesaplanmış $\mathrm{S} / \mathrm{N}$ oranlarına ait değerler sinyal gürültü oranları Çizelge 4 'te verilmiştir.

Çizelge 4. Çalışmada kullanılan L9 ortogonal dizisi, faktörler, incelme (\%) ölçüm sonuçları ve $\mathrm{S} / \mathrm{N}$ oranları

\begin{tabular}{|c|c|c|c|c|c|c|}
\hline \multirow{2}{*}{$\begin{array}{c}\text { Deney } \\
\text { No }\end{array}$} & \multicolumn{3}{|c|}{ Sembol } & $\begin{array}{c}\text { Son Kalınlık } \\
\text { Ortalamasi } \\
(\mathbf{m m})\end{array}$ & $\begin{array}{c}\text { \% } \\
\text { Incelme }\end{array}$ & S/N \\
\hline 1 & 1 & 1 & 1 & 1,4710 & 1,933 & 5,7246 \\
\hline 2 & 1 & 2 & 2 & 1,4603 & 2,647 & 8,4551 \\
\hline 3 & 1 & 3 & 3 & 1,4492 & 3,387 & 10,5963 \\
\hline 4 & 2 & 1 & 2 & 1,4520 & 3,200 & 10,1030 \\
\hline 5 & 2 & 2 & 3 & 1,4468 & 3,547 & 10,9972 \\
\hline 6 & 2 & 3 & 1 & 1,4486 & 3,427 & 10,6983 \\
\hline 7 & 3 & 1 & 3 & 1,4470 & 3,533 & 10,9629 \\
\hline 8 & 3 & 2 & 1 & 1,4440 & 3,733 & 11,4412 \\
\hline 9 & 3 & 3 & 2 & 1,4420 & 3,867 & 11,7475 \\
\hline
\end{tabular}

Enjeksiyon parametrelerinin, incelme oran1 üzerindeki etkinliğini belirlemek için Şekil 4' teki gibi parça boyunca 9 nokta üzerinden ölçümler alınmıştır. Şekillendirme sonrası parçaların kesitleri boyunca farklı bölgelerinde meydana gelen kalınlık değişimlerini görebilmek amacıyla en düşük incelme oranı ve en yüksek incelme oranını veren 1 ve 9 nolu deneylere ait ölçüm sonuçları verilmiştir. Şekil 4'te verilen ölçüm metodu, tüm deney numuneleri için gerçekleştirilmiştir.

Al-1050.O malzemesinin farklı proses parametreleri kullanılarak plastik enjeksiyonuyla şekillendirilmesi sonucu ölçülen incelme sonuçları Minitab 17 programı kullanılarak analiz edilmiştir. Kontrol faktörlerinin incelme üzerindeki etkilerini belirleyebilmek amaciyla $\mathrm{S} / \mathrm{N}$ yanit tablosu oluşturulmuştur (Çizelge 5). Her faktörün farklı seviyelerinden elde edilen maksimum ve minimum ortalama gürültü oranları arasındaki farkların daha 
Sac Metallerin Şekillendirilmesinde Yeni bir Uygulama: Plastik Enjeksiyon Kalıplamada Sıvı Basincıyla Metallerin Şekillendirilmesi

fazla ya da daha az olması faktörlerin incelme üzerindeki etkinliği hakkında bilgi vermektedir. Farkların işaretine bakılmaksızın seviyeleri arasında büyük farka sahip olan kontrol faktörünün sonuç üzerinde daha etkili olduğu göz önüne alındığında Çizelge 5'e göre incelme üzerinde en etkili parametrelerin sirasıyla enjeksiyon basıncı (A), ergiyik sıcaklığı (B) ve enjeksiyon hızı (C) olduğu görülmektedir.
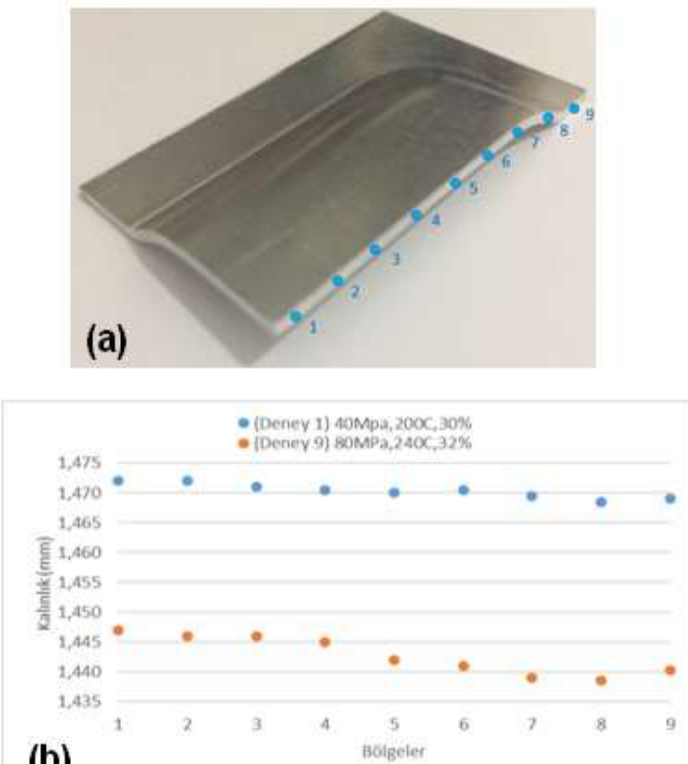

(b)

Şekil 4. Kalınlık Değişimleri (a) Ölçüm alınan bölgeler (b) 1 ve 9 nolu deneyler için kalınlık değişimlerinin dağılımı

Çizelge 5. (S/N) ortalamaları için yanıt tablosu

\begin{tabular}{|c|c|c|c|c|c|}
\hline \multirow{2}{*}{ 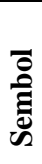 } & \multirow{2}{*}{ 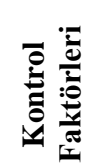 } & \multicolumn{4}{|c|}{ S/N Ortalamaları } \\
\hline & & Seviye 1 & Seviye 2 & Seviye 3 & Max-Min \\
\hline A & $\begin{array}{c}\text { Enj. } \\
\text { Basnç. } \\
\text { (MPa) }\end{array}$ & 8,25867 & 10,5995 & 11,3838 & 3,12513 \\
\hline B & $\begin{array}{l}\text { Erg. } \\
\text { Sic. } \\
\left({ }^{\circ} \mathrm{C}\right)\end{array}$ & 8,93017 & 10,2978 & 11,014 & 2,08383 \\
\hline $\mathrm{C}$ & $\begin{array}{l}\text { Enj. } \\
\text { Hizi } \\
(\%)\end{array}$ & 9,28803 & 10,1018 & 10,8521 & 1,56407 \\
\hline
\end{tabular}

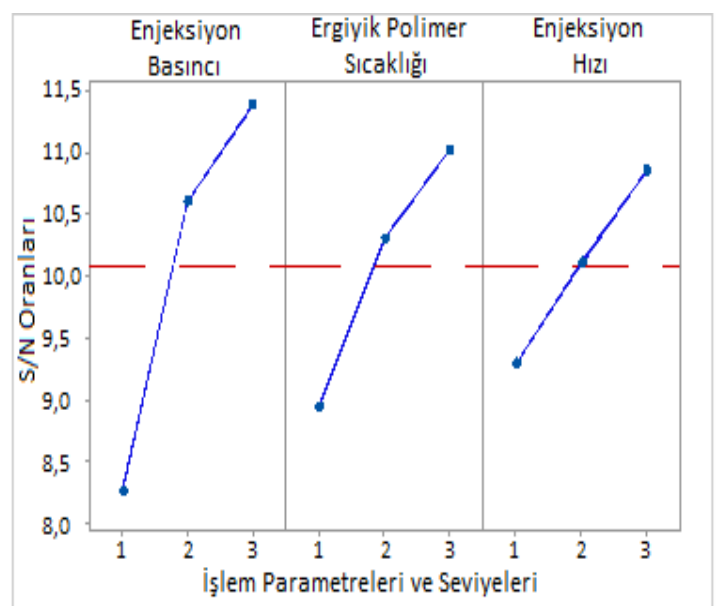

Şekil 5. (\%) İncelme oranları için ortalama $\mathrm{S} / \mathrm{N}$ grafiği (Daha büyük daha iyi)

Şekil 5'te kontrol faktörleri ve seviyelerine ait S/N oranları görülmektedir. Şekillendirme sonrasında 1,5 mm'lik alüminyum plakalar için parçada meydana gelen incelme miktarının maksimum olmasının istenmesinden dolayı en büyük en iyidir kalite karakteristiğine göre yapılan optimizasyona göre, incelme miktarının en büyük olduğu seviyelerin, 80 MPaenjeksiyon basıncında, $240{ }^{\circ} \mathrm{C}$ ergiyik sıcaklığında ve \%34 enjeksiyon hızında olduğu görülmüştür. Buna göre maksimum incelmeyi sağlayan şekillendirme parametreleri "A3-B3-C3" olarak belirlenmiştir. Yapılan deneysel çalışmada incelme değerlerinin optimal sonuçları elde edilmiştir. İncelme için optimum sonuca mevcut deneylerden ulaşılamamıştır. Bu nedenle ilave bir doğrulama deneyine ihtiyaç duyulmuştur. Yapılan doğrulama deneyi sonucunda, herhangi bir şekillendirme kusuru görülmeksizin elde edilmiş olan kalınlık değeri ise 1,4395 mm olarak ölçülmüştür.

\section{Varyans Analiz Metodu}

Plastik enjeksiyon kalıplama yöntemi ile şekillendirilmiş parçaların kalınlık değişimlerini etkileyen kontrol faktörlerinin sonuç üzerindeki \% katkı oranlarını belirleyebilmek amacıyla Varyans Analizi (ANOVA) kullanılmıştır. Her bir kontrol faktörünün incelme üzerindeki \% katkı oranları Minitab 17 programından faydalanılarak \%95 güvenilirlik seviyesinde hesaplanmıştır. 
Çizelge 6'da her kontrol faktörüne ait \% katkı oranları verilmiştir. Buna göre incelme üzerinde en etkili parametrelerin sirasiyla; Enjeksiyon Basıncı: A $(59,84 \%)$, Ergiyik Sicaklığı: B $(23,46 \%)$ ve Enjeksiyon Hızı: C $(10,75 \%)$ olduğu gözlemlenmiştir.

Çizelge 6. (\%) İncelme oranları için varyans analizi

\begin{tabular}{|c|c|c|c|c|c|c|}
\hline 敬 & 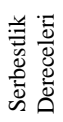 & 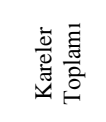 & 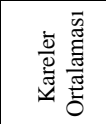 & $\begin{array}{l}\text { 芯 } \\
\text { Oे } \\
\text { I }\end{array}$ & 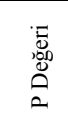 & 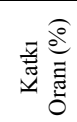 \\
\hline A & 2 & 0,000395 & 0,00019 & 10,38 & 0,088 & 59,84 \\
\hline B & 2 & 0,000155 & 0,000078 & 4,07 & 0,197 & 23,46 \\
\hline $\mathrm{C}$ & 2 & 0,000071 & 0,000035 & 1,86 & 0,349 & 10,75 \\
\hline Hata (e) & 2 & 0,000038 & 0,000019 & - & - & 5,75 \\
\hline Toplam & 8 & 0,000660 & - & - & - & 100 \\
\hline
\end{tabular}

ANOVA sonuçları incelendiğinde Taguchi metoduyla elde edilen sonuçlarla paralellik gösterdiği görülmektedir. Her iki analizde de incelme üzerinde en fazla etkiye sahip parametre olarak enjeksiyon basincı ve en az etkiye sahip parametre olarak ise enjeksiyon hızı bulunmuştur [13].

\section{Regresyon Analizi}

Al-1050.O malzemesinin plastik enjeksiyon yöntemiyle şekillendirilmesi sonucu parçalarda meydana gelen incelme miktarlarının tahmini için regresyon analizi ve cevap-yüzey metodu kullanılarak birinci ve ikinci dereceden tahminsel denklemler geliştirilmiştir. Lineer regresyon analizi ile elde edilen tahminsel denklemin korelasyon katsayıs1 $\mathrm{R}^{2}=0,907 \quad$ olarak hesaplanmıştır (Eşitlik 2). Eşitliğin oluşturulmasında kullanılan katsayılar Çizelge 7'de gösterilmiştir. Korelasyon katsayısının yüksek olması elde edilen denklemin \%90,7 doğruluğunda ve oldukça güvenilir olduğunun bir göstergesidir. $\mathrm{Bu}$ denklemin kullanılmasıyla 1,5 mm kalınlığındaki plakalar için mevcut deneylerden ulaşılamayan optimum A3-B3-C3 (80 MPa-240 $\left.{ }^{\circ} \mathrm{C}-\% 34\right)$ seviyelerine ait tahminsel kalınlık değeri $1,4350 \mathrm{~mm}$ olarak hesaplanmıştır. (Şekil 5).
Kalınlı $(\mathrm{mm})=1,5853-0,000396 . \mathrm{A}-0,000252 . \mathrm{B}-0,001717 . \mathrm{C}$

Çizelge 7. Regresyon analizine ait katsay1lar \begin{tabular}{|c|l|l|l|l|} 
Kaynak & Katsayılar & SE Katsayılar & T-Değeri & P-Değeri \\
\hline
\end{tabular}

\begin{tabular}{|c|l|l|l|l|}
\hline Sabit & 1,5853 & 0,0280 & 56,56 & 0,000 \\
\hline A & $-0,000396$ & 0,000071 & $-5,55$ & 0,003 \\
\hline B & $-0,000252$ & 0,000071 & $-3,53$ & 0,017 \\
\hline C & $-0,001717$ & 0,000713 & $-2,41$ & 0,061 \\
\hline
\end{tabular}

\section{Cevap Yüzey Metodu}

Sac metallerin şekillendirme sonrası kalınlık değerlerinin tahmini cevap yüzey metodu kullanılmıştır. Cevap yüzey metodu ile elde edilen ikinci dereceden tahminsel denklem kullanılarak Taguchi deneysel tasarımında yer alan belirli parametre değerlerine bağlı kalmaksızın kontrol faktörlerine ait istenilen ara değerler denklemde yerine yazılarak gerçeğe en yakın kalınlık değerleri tahmin edilebilmektedir (Eşitlik 3). Bu eşitlikte kontrol faktörlerinin birbirleriyle etkileşimleri de dikkate alınmaktadır. Denklemin kullanılması ile 1,5 mm kalınlığındaki plakalar için mevcut deneylerden ulaşılamayan optimum A3-B3-C3 (80 $\left.\mathrm{MPa}-240^{\circ} \mathrm{C}-\% 34\right)$ seviyelerine ait tahminsel kalınlık değeri 1,4417 mm olarak hesaplanmıştır. Şekil 6'da hem deneysel sonuçlar hem de tahmin denklemlerinden elde edilen sonuçlar birlikte verilmiş ve sonuçların birbirileri ile uyumlu olduğu görülmüştür.

Kalınlık $(\mathrm{mm})=1,8-0,004899 . \mathrm{A}+0,000211 . \mathrm{B}-0,01181 . \mathrm{C}+$ $0,000008 . A^{2}-0,000001 . B^{2}+0,000079 . C^{2}+0,000003$.A.B + 0,000089.A.C

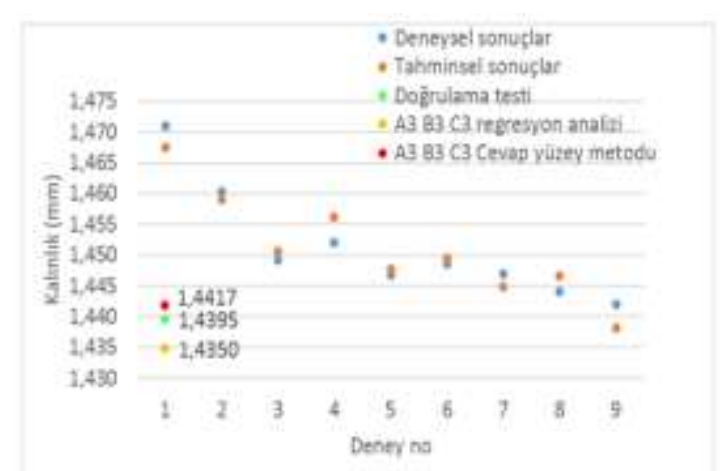

Şekil 6. 1,5 mm kalınlığında alüminyum saclar için şekillendirme sonrası deneysel ve tahminsel kalınlık değerleri 
Değişen enjeksiyon basıncı ve ergiyik polimer sıcaklığının kalınlık üzerindeki etkilerine ait cevap yüzey metoduyla oluşturulan yüzey grafiği Şekil 7'de gösterilmiştir. Verilen yüzey grafiği incelendiğinde Taguchi ve ANOVA da olduğu gibi enjeksiyon basıncının incelme üzerinde diğer parametrelere kiyasla daha etkili olduğu anlaşılmaktadır [20].

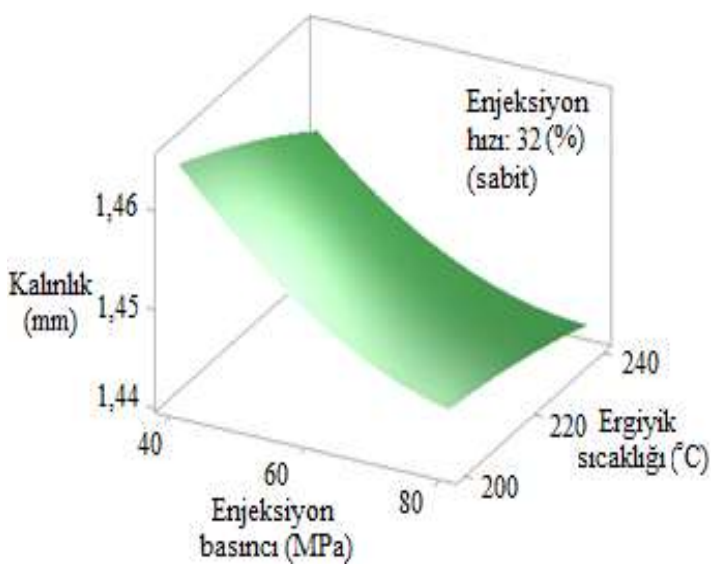

Şekil 7. Enjeksiyon basınc1-Ergiyik polimer sıcaklığı-Sac metal kalınlık yüzey grafiği

Şekillendirilmiş alüminyum parçaların köşe yarıçapları optik komperatör ile yapılan ölçümler ile elde edilmiştir. Ölçümler neticesinde artan parametre değerlerine bağlı olarak köşe yarıçapı (radyüs) değerlerinin azaldığı görülmüştür. Şekillendirilen parçalar arası farkı göstermek amacıyla, deneysel çalışmada elde edilen 9 set deneyden en yüksek (9 nolu deney)-orta (5 nolu deney)-en düşük (1 nolu deney) incelme oranı veren numunelere ait köşe yarıçapı görüntüleri Şekil 8'de verilmiştir. Çizelge 8'de da deney planına ait tüm numunelerin köşe yarıçapı değerleri verilmiştir. Elde edilen bu sonuçların, Çizelge 4'de verilen incelme oranları ile uyumlu olduğu görülmüştür. Sac metalin şekillendirilebilirliğini gösteren incelme oranı arttıkça, yarıçap değeri azalmıştır. Yarıçap değerinin azalması, sacın kalıp içinde daha yüksek oranda şekillendirildiğini göstermektedir. Deney setinden en az incelme oranı veren 1 nolu numune ile en yüksek incelme oranı veren 9 nolu numuneye ait yarıçap değerleri karşılaştırıldığında, yarıçap değerinde, \%36 azalma görülmüştür.
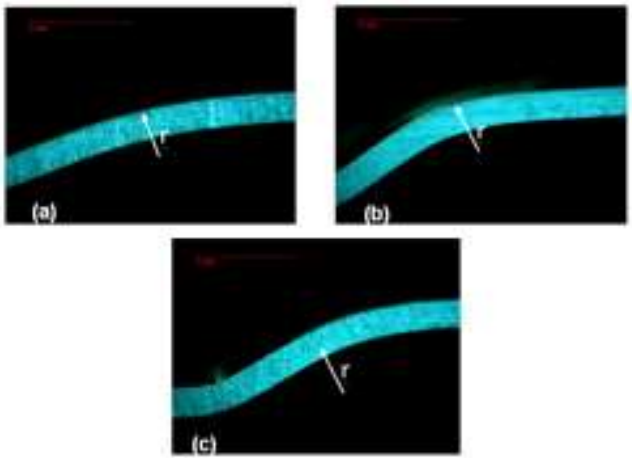

Şekil 8. Proses sonu parça köşe yarıçapı formları (a) 1 no'lu deney (b) 5 no'lu deney (c) 9 no'lu deney

\section{2. Şekillendirilmiş Parçanın Sertlik Ölçümleri}

Proses parametrelerinin sertlik üzerine etkilerini görebilmek amacıyla gerçekleştirilen Rockwell sertlik deneyi ile saf ve şekillendirilmiş alüminyum plakaların sertlik değerleri ölçülmüştür. Yapılan ölçümler sonucunda farklı proses parametreleri kullanılarak şekillendirilmiş parçaların, proses parametrelerinin artmasına bağlı olarak sertlik değerlerinde bir yükselişin olduğu görülmüştür. $\mathrm{Bu}$ yükselişin temel nedeni, proses parametrelerinin artması ile şekillendirilebilirliğin artması ve bunun sonucunda malzemenin daha çok pekleşerek sertlik kazanmasıdır. Çizelge 8'de saf ve şekillendirilmiş numunelerin HRB cinsinden enine ve boyuna ortalama sertlik değerleri verilmiştir. Şekil 9'da örnek bir numune üzerinden alınan sertlik ölçüm değerleri verilmiştir.

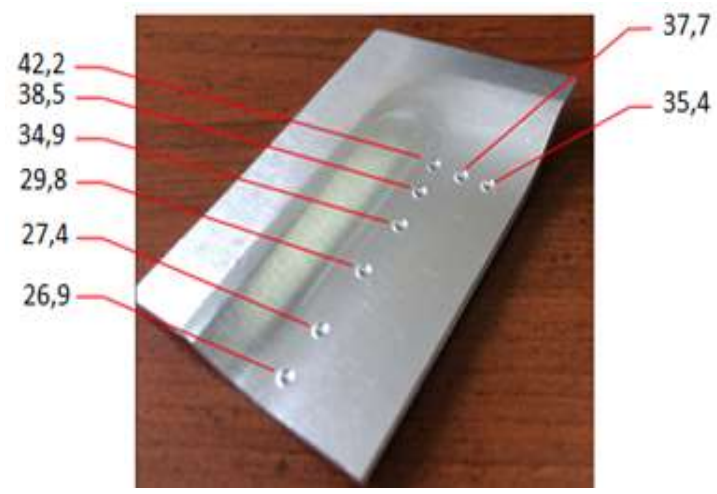

Şekil 9. Numune üzerinde sertlik ölçümü 
Çizelge 8. Ortalama sertlik değerleri

\begin{tabular}{|c|c|c|c|c|c|c|}
\hline \multirow[t]{2}{*}{$\begin{array}{c}\text { Deney } \\
\text { No }\end{array}$} & \multicolumn{3}{|c|}{ Semboller } & \multicolumn{2}{|c|}{$\begin{array}{c}\text { Sertlik } \\
\text { Değerleri } \\
\text { [HRB] }\end{array}$} & \multirow[t]{2}{*}{$\begin{array}{c}\text { Köşe yarıçap } \\
\text { değerleri } \\
(\mathbf{m m})\end{array}$} \\
\hline & $\mathbf{A}$ & B & C & Enine & Boyuna & \\
\hline Saf & - & - & - & \multicolumn{2}{|c|}{ Ort. 22,8 } & \\
\hline 1 & 1 & 1 & 1 & 31,9 & 28,2 & 31,25 \\
\hline 2 & 1 & 2 & 2 & 32,6 & 28,5 & 23,75 \\
\hline 3 & 1 & 3 & 3 & 33,2 & 29,1 & 15,00 \\
\hline 4 & 2 & 1 & 2 & 33,8 & 29,1 & 22,50 \\
\hline 5 & 2 & 2 & 3 & 34,5 & 31,0 & 13,75 \\
\hline 6 & 2 & 3 & 1 & 35,0 & 31,2 & 16,87 \\
\hline 7 & 3 & 1 & 3 & 36,8 & 32,9 & 12,50 \\
\hline 8 & 3 & 2 & 1 & 37,0 & 33,3 & 11,25 \\
\hline 9 & 3 & 3 & 2 & 37,2 & 34,1 & 11,25 \\
\hline
\end{tabular}

Çizelge 8 incelendiğinde, şekillendirilmiş malzemelerin enine ve boyuna ortalama sertlik değerlerinin birbirinden farklı olduğu görülmektedir. $\mathrm{Bu}$ farklılığın temel nedeni enjeksiyondaki basınç dağılımıdır. Ergiyik polimerin kalıp içerisinde izlemiş olduğu yol, parçaların farklı doğrultularında farklı deformasyon derecelerine sahip olduğunu göstermektedir. Ayrıca şekillendirilmiş parçalar üzerindeki sertlik değişimlerine bakıldığında, köşe yarıçap1 bölgesine eşit uzaklıkta yapılan ölçümlerde sertlik değerlerinin giderek arttığ 1 görülmüştür. Artan deformasyon derecesi, mikro yapıda depolanan enerjinin ve dislokasyon yoğunluğunun artmasına neden olmuştur [21-24]. Bu durumda da malzemenin sertliği artmış ve köşe bölgelerinde malzeme akışının zorlanması ve pekleşmesi söz konusu olmuştur. Şekillendirilen parçalarda bu sertlik artışına rağmen herhangi bir yırtılma görülmemiştir.

\section{SONUÇ}

Yapılan çalışmada, plastik enjeksiyon yöntemi, alışılmışın dışında, sac metallerin şekillendirilmesi için kullanılmıştır. Yöntemde, sıvı basıncı ile şekillendirme prensibi esas alınıp, enjeksiyon basıncı, ergiyik sıcaklığı ve enjeksiyon hızı parametreleri farklı seviyelerde kullanılmıştır. Elde edilen sonuçlar şu şekildedir:

Enjeksiyon parametrelerinin sac metalin şekillendirilebilirliği üzerine etkileri incelendiğinde, sırasıyla enjeksiyon basıncı: A $(\% 59,84)$, ergiyik sicaklığı: B $(\% 23,46)$ ve enjeksiyon hız: $\quad$ C $\quad(\% 10,75) \quad$ olduğu gözlemlenmiştir. Proses sonu şekillendirilmiş parçalardaki kalınlık değişimleri dikkate alındığında, parçaların flanş bölgelerinde diğer bölgelere oranla daha fazla incelmenin meydana geldiği görülmüştür.

Deneysel çalışmadaki kontrol faktörlerinin üçüncü seviyeleri $\left(\mathrm{A}=80 \mathrm{MPa}, \mathrm{B}=240{ }^{\circ} \mathrm{C}, \mathrm{C}=\% 34\right)$, şekillendirilmiş parçada herhangi bir kusur görülmeksizin, en yüksek şekillendirilebilirliği sağlayan optimum seviyeler olarak belirlenmiştir. Taguchi, regresyon analiz, ANOVA ve cevapyüzey metodu kullanılarak elde edilen sonuçların birbirleri ile uyumlu oldukları, birinci ve ikinci dereceden tahminsel denklemler ile hesaplanan değerlere yakın sonuçlar verdiği görülmüştür. Geliştirilen tahminsel denklemin korelasyon katsayısı $\mathrm{R}^{2}=0,907$ olarak hesaplanmıştır.

Maksimum şekillendirilebilirliğin elde edildiği 3-3-3 deney kombinasyonu için belirlenen inceleme oranı \%3,867 iken en düşük parametre seviyeleri (1-1-1) ile gerçekleştirilen şekillendirme işlemi sonrası ölçülen incelme oranı \%1,933’tür.

Proses parametrelerinden özellikle enjeksiyon basıncı ve enjeksiyon hızı değerlerinin artmasına bağlı olarak şekillendirilen parçada deformasyon oranı ve dislokasyon yoğunluğu artmış ve buna bağlı olarak da sertlik değerlerinde artış olmuştur. Şekillendirme öncesi plakanın 22 HRB olan sertlik değerinin, şekillendirme sonrası 34 HRB değerine ulaştığı görülmüştür.

\section{KAYNAKLAR}

1. Padmanabhan, R., Oliveria, M.C., Alves, J.L., Menezes, L.F., 2007. Influence of Process Parameters on the Deep Drawing of Stainless Steel, Finite Elements in Analysis and Design, 43, 1062-1067.

2. Raju, S., Ganesan, G., Karthikeyan, R., 2010. Influence of Variables in Deep Drawing of AA 6061 sheet, Transactions of Nonferrous Metals Society of China, 20, 1856-1862.

3. Lin, B.T., Yang, C.Y., 2017. Applying the Taguchi Method to Determine the Influences of 
a Micro Ridge Punch Design on the Deep Drawing, Int J Adv Manuf Technol., 88, 2109-2111.

4. Port, A.L., Toussaint, F., Arrieux, R., 2009. Finite Element Study and Sensitive Analysis of the Deep-drawing Formability of Commercially Pure Titanium, Int $\mathrm{J}$ Mater Form., 2, 121-129.

5. Yagami, T., Manabe, K., Yamauchi, Y., 2007. Effect of Alternating Blank Holder Motion of Drawing and Wrinkle Elimination on Deep Drawability, J Mater Process Technol., 187-188, 187-191.

6. Koç, M., Ağçayazı, A., Carsley, J., 2011. An Experimental Study on Robustness and Process Capability of the Warm Hydroforming Process, Journal of Manufacturing Science and Engineering, 133(02), 1-13.

7. Yaşar, M., Kadı, İ., Evlen, H., 2011. AA 5754 Sacının Farklı Sıcaklıklarda Hidrolik Akışkanla Şekillendirilmesi. $6^{\text {th }}$ International Advanced Technologies Symposium (IATS'11), Elazı̆̆ Turkey, 136-140.

8. Li, B., Nye, T.J., Metzger, R., 2006. MultiObjective Optimization of Forming Parameters for Tube Hydroforming Process Based on the Taguchi Method, International Journal Advanced Manufacturing Technologies, 28, 23-30.

9. Michaeli, W., Maesing, R., 2010. Injection Moulding and Metal Forming in One Process Step. 25 ${ }^{\text {th }}$ International Plastics Technology Colloquium of the Institute of Plastics Processing (IKV), RWTH Aachen University, Germany

10. Lucchetta, G., Baesso, R., 2006. Polymer lnjection Forming (PIF) of Thin-Walled Sheet Metal Parts-Preliminary Experimental Results, $10^{\text {th }}$ Esaform Conference on Material Forming, Zaragoza-Spain, 907, 1046-1051.

11. Chen, M., Zhang, X., Lei, Q., Fu, J., 2002. Finite Element Analysis of Forming of Sheet Metal Blank in Manufacturing Metal/Polymer Macro-Composite Components via Injection Moulding, International Journal of Machine Tools \& Manufacture, 42, 375-383.

12. Altan, M., Bayraktar, M., Yavuz, B., 2016. Manufacturing Polymer/Metal Macro Composite Structure for Vibration Damping,
International Journal of Advanced Manufacturing Technologies, 86, 2119-2126.

13. Tekkaya, A.E., Hussain, M.M., Witulski, J., 2012. The Non-Hydrostatic Responce of Polymer Melts as a Pressure Medium in Sheet Metal Forming, German Academic Society for Production Engineering (WGP), 6, 385-394.

14. Bariani, P.F., Bruschi, S., Ghiotti, A., Lucchetta, G., 2007. An Approach to Modelling the Forming Process of Sheet MetalPolymer Composites, 56(1), 261-264.

15. Behrens, B.A., Bouguecha, A., Götze, T., 2010. Consideration of Fundamental Influence Parameters for the Simulation of Sheet-Metal Forming Processes by Means of Plastic Melt Pressure, Materialwissenschaft und Werkstofftechnik, 41(10), 839-843.

16. Landgrebe, D., Krausel, V., Rautenstrauch, A., Albert, A., Werteim, R., 2016. EnergyEfficiency in a Hybrid Process of Sheet Metal Forming and Polymer lnjection Moulding, Procedia CIRP, 40, 109-114.

17. Parsa, M.H., Darbandi, P., 2008. Experimental and Numerical Analyses of Sheet Hydroforming Process for Production of an Automobile Body Part, Journal of Materials Processing Technology, 198, 381-390.

18. Yuan, S.J., Han, C., Wang, X.S., 2006. Hydroforming of Automotive Structural Components with Rectangular-Sections, International Journal of Machine Tools \& Manufacture, 46, 1201-1206.

19. Ross, P.J., 1996. Taguchi Techniques for Quality Engineering (Second Edition), McGraw Hill, New York, USA, p. 327.

20. Adeosun, S.O., Sekunowo, O.I., Balogun, S.A., Osoba, L.O., 2011. Effect of Deformation on the Mechanical and Electrical Properties of Aluminum-Magnesium Alloy, Journal of Minerals \& Materials Characterization \& Engineering, 10 (6), 553-560.

21. Şen, M., Ekşi Altan, M., 2017 Plastik Enjeksiyon Kalıplama Yöntemi ile Sac Metallerin Şekillendirilmesinin İncelenmesi, Marmara Fen Bilimleri Dergisi, 1, 39-47.

22. Abdulhaqq, A., Hamid, P., Ghosh, S., Jain, O., Subrata, R., 2005. Processing, Microstructure and Mechanical Properties of Cast in-situ Al $(\mathrm{Mg}, \mathrm{Mn})-\mathrm{Al}_{2} \mathrm{O}_{3} \quad\left(\mathrm{MnO}_{2}\right) \quad$ Composites, 
Metallurgical and Materials Transactions A, 36A, 221-230.

23. Nafsin, N., Rashed, H.M.M.A., 2013. Effects of Copper and Magnesium on Microstructure and Hardness of Al-Cu-Mg Alloys, International Journal of Engineering and Advanced Technology (IJEAT), 2(5), 533-536.

24. Adeosun, S.O., Ayoola, W.A., Bodude, M., Sanni, S.O., 2011. Strength and Hardness of Directionally- Rolled AA1230 Aluminum Alloy, Journal of Emerging Trends in Engineering and Applied Sciences, 2(3), 440-444. 
